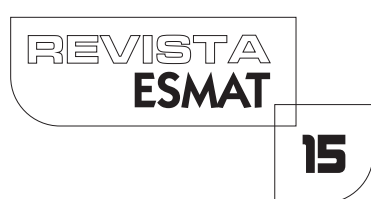

\title{
POBREZA ENERGÉTICA: uma nova espécie de pobreza?
}

ENERGY POVERTY: a new kind of poverty?

CarlaAmado Gomes

Professora Auxiliar da Faculdade de Direito da Universidade de Lisboa; professora convidada da Faculdade de Direito da Universidade Católica do Porto. Investigadora do Centro de Investigação de Direito Público (CIDP); supervisora científica da linha de pesquisa Energia, Recursos Naturais \& Ambiente. Foi professora convidada da Faculdade de Direito da Universidade Nova de Lisboa entre 2007 e 20 I3. Lecciona cursos de Mestrado e Pós-Graduação em Direito do Ambiente, Direito Administrativo e Direito da Energia, em Angola, Moçambique e Brasil. Colabora regularmente em ações de formação no Centro de Estudos Judiciários.

\section{RESUMO}

A pobreza energética é um problema antigo, mas de descoberta recente. Assumindo diferentes formas consoante estejamos num contexto de Estados desenvolvidos e Estados em desenvolvimento e não tendo uma definição oficial, a pobreza energética é causa de problemas de saúde e défice de direitos, devendo ser adoptadas políticas públicas no sentido de erradicá-la.

PALAVRAS CHAVE: Pobreza; Energia; Eficiência Energética; Direitos Humanos.

\section{ABSTRACT}

Energy poverty is an old problem though just recently discovered. It assumes different forms depending on the context of developed and developing States and does not have an official definition. Energy poverty is a cause of several health problems and generates a deficit of rights, so public policies must be adopted to eradicate it.

KEYWORDS: Poverty; Energy; Energy Efficiency; Human Rights. 


\section{INTRODUÇÃO}

Quando, em novembro de 2016, os telejornais espanhóis e europeus abriram as suas emissões com a notícia da morte de uma senhora de $8 \mathrm{I}$ anos provocada por uma vela que caíra e incendiara a casa onde morava, na Catalunha, poderia ser apenas mais um relato de uma situação de vulnerabilidade que acomete os idosos. No entanto, a notícia espoletou um debate nacional e reavivou a atenção da doutrina para um fenómeno crescente em Espanha e em vários Estados da União Europeia: a pobreza energética'. É que Rosa, a falecida, iluminava a sua casa com velas por não ter dinheiro para pagar a conta da luz e a companhia lhe ter cortado o fornecimento...

A pobreza energética é um tema difícil por um número conjugado de razões, das quais apenas adiantaremos, por ora, duas: por um lado, o fenómeno manifesta-se diferentemente em Estados desenvolvidos e Estados em desenvolvimento ${ }^{2}$; por outro, inexiste uma definição "oficial" ou mesmo consensual, o que dificulta o desenho de políticas voltadas para a resolução do problema. Tendo começado a ser estudado, na Europa, por Brenda BOARDMAN, no Reino Unido, na década de $1990^{3}$, o tema temse alimentado tanto da situação de vulnerabilidade gerada pela crise económica de 2008-20 I2, um pouco por todo o mundo, mas muito particularmente nos EstadosMembros da União Europeia do Sul da Europa ${ }^{4}$, como pelo aumento dos preços da energia induzido pela liberalização do mercado da energia, que penalizou particularmente os antigos Estados satélites da União Soviética.

Segundo a Agência Internacional da Energia, 16\% da população mundial não têm acesso à electricidade, e 38\% da mesma população não dispõem de equipamentos de cozinha ${ }^{5}$. Apesar de os progressos de 2016 serem animadores, sobretudo na Índia, com uma das mais bem-sucedidas histórias de electrificação massiva, há ainda hoje mais pessoas sem acesso à electricidade do que no início do século $X X l^{6}$. Por seu turno, o

' Para uma análise do fenómeno na União Europeia, Stefan BOUZAROVSKI, Sergio TIRADO HERRERO, The energy divide: Integrating energy transitions, regional inequalities and poverty trends in the European Union, in European Urban and Regional Studies, 2017/I , pp. 69 segs.

${ }^{2}$ Cfr. Alexandru MAXIM et alli., Implications and Measurement of Energy Poverty across the European Union, in Sustainability, 2016/5, pp. 483 segs., 487: "the term "energy poverty" can refer to two different socioeconomic issues, depending on the geographical scope of its application: energy affordability in higher income and developed states; inadequate access to 'modern' energy services in most low income or developing countries".

${ }^{3}$ Cfr. Brenda BOARDMAN, Fuel poverty: from cold homes to affordable warmth, Londres, 1991.

${ }^{4}$ Cfr. Marinella DE FOCATIS, Povertà energetica e cliente vulnerabile tra ragioni di stato e di mercato, in Esperienze regolatorie europee a confronto nel settore dell'energia : atti del convegno Aiden (Milano, 3 dicembre 20 I 5), coord. de Eugenio Bruti Liberati, Marinella De Focatiis, Aldo Travi, Milão, 2017, pp. 101 segs. 
relatório europeu sobre rendimento e condições de vida na União Europeia concluía, em 2012, de uma banda, que 54 milhões de cidadãos da União Europeia (ou seja, 10.8\% da população da União Europeia) não conseguem manter a sua casa adequadamente quente; de outra, que, no verão de 2003, as 80.000 pessoas que morreram na vaga de calor que assolou a Europa teriam perecido em razão de não conseguirem manter as suas casas suficientemente frescas. ${ }^{7}$

Diagnósticos desse tipo justificam que o Objectivo 7 da Agenda 2030 - Objectivos do Desenvolvimento Sustentável da ONU - seja consagrado ao tema do acesso a fontes de energia fiáveis, sustentáveis e modernas. Como pode ler-se no instrumento citado, esse objectivo traduz-se em:

- "Até 2030, assegurar o acesso universal, de confiança, moderno e a preços acessíveis aos serviços de energia;

- Até 2030, aumentar substancialmente a participação de energias renováveis na matriz energética global;

- Até 2030, duplicar a taxa global de melhoria da eficiência energética;

- Até 2030, reforçar a cooperação internacional para facilitar o acesso à investigação e às tecnologias de energia limpa, incluindo energias renováveis, eficiência energética e tecnologias de combustíveis fósseis avançadas e mais limpas, e promover o investimento em infraestrutura de energia e em tecnologias de energia limpa;

- Até 2030, expandir a infraestrutura e modernizar a tecnologia para o fornecimento de serviços de energia modernos e sustentáveis para todos nos países em desenvolvimento, particularmente nos países menos desenvolvidos, nos pequenos Estados insulares em desenvolvimento e nos países em desenvolvimento sem litoral, de acordo com seus respectivos programas de apoio".

No plano da União Europeia, o Pacote Legislativo da Comissão Europeia Clean Energy for all Europeans, publicado em novembro de 2016, e que pretende rever a legislação da União Europeia no sector da Energia ${ }^{8}$, dedica especial atenção à pobreza energética. No documento de trabalho sobre Boas práticas de eficiência energética ${ }^{9}$, o tema da pobreza energética é encarado como um problema cuja solução de longo prazo passa sobretudo pela reabilitação de edifícios e dos sistemas de aquecimento e arrefecimento, no sentido de os tornar mais eficientes. ${ }^{10}$

${ }^{5}$ http://www.worldenergyoutlook.org/resources/energydevelopment/energyaccessdtatabase/

${ }^{6}$ IEA - Energy Access Outlook 2017 - https://www.iea.org/access20 $17 /$

${ }^{7}$ Cfr. Energy poverty and vulnerable consumers in the energy sector across the EU: analysis of policies and measures, coord. de Steve Pye (UCL), Audrey Dobbins (USTUTT), Insight EU Policy Report 2, Maio de 20 I 5, disponível em http://www.insightenergy.org 


\section{ADIFICULDADE DO CONCEITO DE "POBREZA ENERGÉTICA"}

'Pobreza energética', já se avançou, pode ter diferentes significados consoante o estádio de desenvolvimento do país. Mas mesmo no seio de países desenvolvidos, a expressão não merece uma leitura unívoca. Para além de 'pobreza energética' ser por vezes denominada como "privação de energia doméstica" ou "precariedade energética", BOUZAROVSKI adverte que a primeira definição do conceito terá sido de ISHERWOOD e HANCOCK (1979), que o identificaram com a situação dos "agregados familiares que gastam duas vezes mais do que a média nacional em combustíveis, luz e outra energia". Essa fórmula foi depois adaptada por BOARDMAN, ligando a pobreza energética à necessidade de gastar mais de 10\% do rendimento mensal em energia doméstica". Existem, todavia, abordagens mais subjectivas, como as de BRADSHAW e HUTTON, que definem "pobreza energética" como a situação dos "indivíduos, famílias e grupos que não têm rendimento satisfatório para providenciar uma casa suficientemente aquecida e iluminada, a avaliar pelos padrões sociais habituais, ou pelo menos recomendáveis, no contexto da sociedade em que se integram" ${ }^{2}$.

Ambas as vias - que admitem muitas variantes - revelam problemas: a primeira, porque não faz menção à dificuldade de saldar a factura energética, apenas aponta para um gasto superior à média ou a 10\% do total do rendimento (gasto que pode ser intencional ou negligente, mas não de levantar problemas de gestão da economia doméstica); a segunda, porque não avalia necessidades absolutas, mas sim relativas, tendo em atenção padrões sociais que podem envolver gastos supérfluos.

\section{I. Pobreza energética como falta de acesso a fontes de energia}

Nos países menos desenvolvidos, o problema da pobreza energética traduz-se, na

\footnotetext{
${ }^{8}$ Todo o pacote pode ser consultado aqui: https://ec.europa.eu/energy/en/news/commissionproposes-new-rules-consumer-centred-clean-energy-transition

${ }^{9}$ Good practice in energy efficiency — Commission Staff working document (Accompanying the document Proposal for a Directive of the European Parliament and of the Council amending Directive 20/2/27/EU on Energy Efficiency): https://ec.europa.eu/energy/sites/ener/files/documents/good_practice_in_ee_-web.pdf

${ }^{10}$ Com dados estatísticos sobre a pobreza energética na União Europeia, ver também o Relatório do Think Tank liderado por Steve Pye e Audrey Dobbins: Energy poverty and vulnerable consumers in the energy sector across the EU: analysis of policies and measures, Policy Report 2, Maio de 20 I5, disponível em www.insightenergy.org .

"Apud Stefan BOUZAROVSKI, Energy poverty in the European Union: Landscapes of vulnerability, in Wiley Interdisciplinary Reviews: Energy \& Environment, 20 I 4/3, pp. 276 segs.

${ }^{12} \mathrm{~J}$. BRADSHAW e S. HUTTON, Social policy options and fuel poverty, in Journal of Economic Psychology, 1983/3, pp. 249 segs.
} 
sua maior latitude, em inexistência de acesso à energia, e, em menor grau, em insegurança de abastecimento e em falta de equipamentos de cozinha, nomeadamente fogões. A Agência Internacional da Energia estimava, em 2016, que I.2 biliões de pessoas ( $16 \%$ da população mundial) não tinham acesso à electricidade e muitas mais tinham acesso muito deficiente. Mais de $95 \%$ dessas pessoas vivem na África subsariana e na Ásia, predominantemente em áreas rurais. No plano dos equipamentos, 2.7 biliões de pessoas (38\% da população mundial) utilizam lenha para cozinhar, não dispondo de fogões e confeccionando os alimentos de forma rudimentar, em espaços pouco ventilados - mais uma vez, residindo na Ásia e na África subsariana ${ }^{13}$.

GONZÁLEZ-EGUINO, chamando a atenção para a também aqui oscilação de fórmulas, parte da síntese de pobreza energética como um nível de consumo energético incapaz de fazer face a necessidades básicas ${ }^{14}$. Numa definição mais completa (e complexa), REDDY caracteriza-a como "a ausência de escolha quanto à acessibilidade de fontes de energia adequadas, económicas, fiáveis, de boa qualidade, saudáveis e ambientalmente benéficas ao desenvolvimento económico e humano" ${ }^{15}$.

Esta fórmula suscita algumas reflexões, a saber:

$>$ a falta de opção sobre o acesso à energia não implica apenas menos conforto físico, mas também a impossibilidade de desenvolver um conjunto de direitos, como o acesso à informação, à educação, ou à participação política. $\bigcirc$ que significa que essa questão não releva apenas a política energética, antes tem reflexos sobre problemas sociais bem mais abrangentes;

$>$ a adequação, frabilidade e qualidade das fontes de energia constituem um conjunto de condições difícil de reunir em muitos Estados em desenvolvimento. $\bigcirc$ recurso mais usual para a produção de calor e luz é a lenha/biomassa, o recurso mais baixo da "escada energética", e aquele que não depende de nenhuma rede de abastecimento. Essa "opção" envolve desflorestação - embora as populações a promovam de forma tendencialmente racional, para não esgotar o recurso -, tem altos custos sanitários e reflecte baixos rendimentos do agregado familiar;

\footnotetext{
${ }^{13}$ http://www.worldenergyoutlook.org/resources/energydevelopment/energyaccessdatabase/

${ }^{14}$ Mikel GONZÁLEZ-EGUINO, Energy poverty: an overview, in Renewable and sustainable energy reviews, 2015, pp. 377 segs, 379.

${ }^{15} \mathrm{~A}$. REDDY, Energy and social issues, in Energy and the challenge of sustainability, World Energy Council and UNEP, New York, 2000, pp. 38 segs, 44 (disponível aqui: http://www.undp.org/content/dam/aplaws/publication/en/publications/environmentenergy/www-ee-library/sustainable-energy/world-energy-assessment-energy-and-thechallenge-of-sustainability/Norld\%20Energy\%20Assessment-2000.pdf)
} 
a dimensão ambientalmente benéfica das fontes de energia prende-se com a transição para a produção de energias renováveis, que depende da introdução de tecnologias de captação de luz solar (painéis fotovoltaicos), da instalação de parques eólicos e da construção de barragens.

Todas essas metodologias envolvem investimentos mais ou menos vultosos, mas, sobretudo no caso dos painéis fotovoltaicos, incrementam a autosuficiência energética de casas e pequenas comunidades, mormente se combinadas com cogeração a partir de resíduos orgânicos e biomassa. Nesse plano, as situações de pobreza energética podem ser o ponto de partida para uma transição energética mais rápida, por meio da produção descentralizada de energia a partir de fontes renováveis ${ }^{16}$.

\subsection{Pobreza energética como incapacidade de manter o ambiente doméstico suficientemente aquecido ou arrefecido e iluminado}

Nos países desenvolvidos, o problema da pobreza energética encontra-se num patamar superior ao do acesso ao abastecimento, podendo envolver dois tipos de questões: por um lado, a incapacidade ou dificuldade de saldar contas de energia, em razão dos altos preços desta e baixos rendimentos do agregado familiar; por outro, a falta de eficiência energética dos edifícios e casas de habitação, que acarreta perdas no confronto entre a energia consumida e o nível de aproveitamento que dela se retira. No primeiro grupo, integram-se os chamados "consumidores vulneráveis", cuja protecção demanda medidas específicas.

\section{I.3. Vulnerabilidade dos consumidores e pobreza energética}

A vulnerabilidade do consumidor é uma situação particular, a mais grave, de pobreza energética. Um consumidor vulnerável não tem capacidade económica para pagar a energia que consome e, por isso, deve ser protegido, quer por medidas de subsidiação, como a tarifa social ou o cheque-energia, quer pela proibição de corte do abastecimento. A directiva 2009/72/CE, do Parlamento Europeu e do Conselho, de 13 de julho (que estabelece regras comuns para o mercado interno da electricidade e revoga a Directiva 2003/54/CE) prevê esta medida no $n^{\circ} 7$ do artigo $3^{\circ}$, no qual se refere expressamente a proibição de desligamento dos consumidores vulneráveis em momentos críticos.

\footnotetext{
${ }^{16}$ Nesse sentido, Mikel GONZÁLEZ-EGUINO, Energy poverty, cit., p. 384; ver também o Relatório da Agência Internacional do Ambiente Energy Access Outlook 2017, já citado supra, onde se pode ler que nos últimos cinco anos as energias renováveis foram responsáveis por um terço das novas ligações à rede, e a produção descentralizada representa 6\% das novas instalações nos últimos cinco anos.
} 
A vulnerabilidade é, portanto, um problema que reclama soluções de tipo emergencial e de curto/médio prazo; já a questão da eficiência energética envolve medidas estruturais, de longo prazo. O primeiro conceito abrange uma faixa marginal da sociedade; o segundo recai sobre a grande maioria dos agregados residentes em edifícios com mais de 20 anos, e a sua resolução é uma questão fundamental para a transição para uma sociedade hipocarbónica.

Deve-se sublinhar ainda que, em certos Estados (como a Irlanda, por exemplo) assiste-se a mais um desdobramento no quadro da vulnerabilidade do consumidor, falando-se em pobreza energética severa e extrema — traduzindo a primeira uma afectação de mais de $15 \%$ do rendimento do agregado familiar a despesas energéticas, e a segunda um gasto de mais de $20 \%$ do mesmo rendimento. Nesses casos, a solução da proibição do desligamento não é suficiente, tendo o Estado que intervir assistencialmente por meio de medidas financeiras de apoio aos consumidores mais frágeis.

\section{MALEFÍCIOSDA POBREZAENERGÉTICA}

Como expressivamente afirma BIROL, nos Estados menos desenvolvidos, a falta de acesso à energia elétrica faz com que o dia termine mais cedo ${ }^{17}$. A leitura é feita à luz de velas, não existem frigoríficos para conservar os alimentos, a comida é cozida em fornos a lenha que normalmente mulheres e crianças passam horas a juntar e carregar para casa, o ar interior é insalubre.

A pobreza energética sob a forma de circunscrição dos consumidores à opção da base da escada energética, ou seja, a biomassa, tem custos graves para a saúde. Casas onde se cozinha e se aquece o ambiente por meio da queima de madeira acumulam fumo, causa de várias doenças respiratórias. Mas a afectação da saúde não é o único custo social desse fenómeno: a electricidade é hoje essencial para o acesso à informação (pela televisão ou internet), para a leitura e formação pessoal, para a conectividade e subsequente possibilidade de dinamização da participação política, para o exercício da actividade profissional, à emancipação das mulheres.

Já no caso da pobreza energética mais presente em países desenvolvidos, ela gera problemas de saúde de várias ordens: por um lado, fisícos; por outro, psicossomáticos ${ }^{18}$.

\footnotetext{
${ }^{17}$ Faith BIROL, Energy Economics: a place for energy poverty in the Agenda?, The energy journal, 2007/3, pp. I segs.

${ }^{18}$ Cfr. Harriet THOMSON, Carolyn SNELL, e Stefan BOUZAROVSKI, Health, Well/Being and Energy Poverty in Europe: A Comparative Study of 32 European Countries, in International Journal of Environmental Research and Public Health, 2017/6, pp. 584 segs.
} 
Quanto aos primeiros, o excesso de frio ou de calor pode gerar problemas respiratórios e cardíacos. Com efeito, a impossibilidade de manter a casa quente ou fria, de acordo com as alturas do ano, pode em última análise determinar a morte dos seus habitantes, sobretudo se integrarem faixas etárias avançadas ou padecerem de doenças degenerativas ${ }^{19}$. Quanto aos segundos, não conseguir manter a casa confortável pode constituir um factor de constrangimento, susceptível de inibir contactos sociais e conduzir a isolamento e depressões. Alguns estudos referem ainda que a ansiedade gerada pela iminência de recebimento de contas de energia elevadas pode igualmente provocar estados depressivos.

Anotam-se igualmente problemas indirectos relacionados com a pobreza energética: por exemplo, um agregado que, para manter a casa quente ou fresca, desvie rendimentos necessários ao custeio da despesa energética, assim provocando carências de outra ordem (alimentares; educacionais; culturais).

\section{LINHAS DE SUPERAÇÃO DA POBREZA ENERGÉTICA}

O fomento do acesso a fontes de energia fiáveis, a preços razoáveis e ambientalmente adequadas, envolve um investimento importante. Segundo GONZÁLEZ-EGUINO, fornecer acesso universal a fontes de energia implicaria um investimento a vinte anos, a uma razão de 35 bilhões de dólares por ano (ou seja, o equivalente a $0.08 \%$ do PIB de Estados da OCDE, ou 25 dólares/ano por cidadão de Estados da OCDE) - o que, sendo vultoso, não se compara com o valor pago em subsidiação a combustíveis fósseis, que ascendeu, em 20 I2, a 544 bilhões de dólares. Se pensarmos que o investimento - além de minimizar a pobreza energética e de contribuir para o aumento de qualidade de vida de milhares de pessoas, gera oportunidades de emprego e potencia novos investimentos - pode-se aproveitar de um recuo dos subsídios aos fósseis e traduzir uma aposta em fontes renováveis, temos uma solução que vai ao encontro dos objectivos de descarbonização ínsitos no Acordo de Paris. O que torna esse investimento abrangido pela lógica de apoio dos Estados mais desenvolvidos aos menos desenvolvidos, podendo traduzir-se tanto em equipamentos como em formação de técnicos, estimulando assim as economias locais (cfr. o artigo 4, $n^{\circ} 5$, do Acordo de Paris).

\footnotetext{
${ }^{19}$ A Organização Mundial de Saúde recomenda a manutenção de uma temperatura interior entre 18 e os $24^{\circ} \mathrm{C}$, que pode sofrer pequenas variações se estiverem em causa grupos de risco (idosos; crianças; pessoas acamadas) — cfr. o relatório Health Impact of Low Indoor Temperatures, WHO Regional Office for Europe: Copenhaga, I 985 http://www.theclaymoreproject.com/uploads/associate/365/file/Health\%20Documents/WHO $\% 20$ - \% 20 health $\% 20 \mathrm{impact} \% 20$ of\% 20 low $\% 20 \mathrm{ind}$ oor $\% 20$ temperatures $\% 20(\mathrm{WHO}, \% 201985) . p d f$
} 
Segundo as projecções da Agência Internacional de Energia, as políticas de combate à pobreza energética nos Estados em desenvolvimento permitirão fazer decrescer o número de pessoas sem acesso a equipamentos de cozinha em um milhão, entre 2015 e 2030, sendo que nas zonas urbanas o recurso à biomassa cairá 40\% - já nas zonas rurais, a previsão para 2030 é que cerca de 60\% ainda necessitem de recorrer à biomassa para confeccionar os alimentos ${ }^{20}$.

No que toca à superação da pobreza energética pelos Estados mais desenvolvidos, a medida mais eficaz passa pela implementação de medidas de eficiência energética nos edifícios. Como a reabilitação é lenta e onerosa, sobretudo quando envolve substituição de abastecimento de sistemas de aquecimento de carvão ou gás para eletricidade ou cogeração a partir de valorização energética de resíduos, tal desígnio não resolve problemas de curtíssimo prazo - como a incapacidade de pagar contas de luz.

As situações emergenciais de pobreza energética são neste plano atalhadas pela concessão de cheques-energia ou da fixação de uma tarifa social que pode ser obtida, em função da prova dos rendimentos do agregado familiar, com o fornecedor de energia, porque a mera financiação das despesas não contribui para solução de longo prazo, existem respostas originais que apelam à formação de uma cultura de contenção energética. Em França, uma solução proposta pelo Mediador Nacional para a Energia consistia na atribuição de um cheque a famílias em situação precária (elegíveis por meio da comprovação do baixo rendimento do agregado), cheque este que poderia ser utilizado para custear as despesas energéticas e/ou para imprimir medidas de eficiência energética no imóvel de residência ${ }^{21}$. Também o programa Habiter mieux (Habitar melhor, 20 l0) pretendeu conceder apoios para incrementar a eficiência energética de habitações de famílias vulneráveis, sobretudo no meio rural ${ }^{22}$.

Já na Alemanha, concebeu-se um esquema-piloto de substituição dos contadores de eletricidade em 660 casas de habitação social ( 1000 Watt Losung), que passa pela redução da potência a I.000 Watt/mês caso, após três notificações de pagamento não cumpridas, o consumidor continue a não liquidar a sua conta com o fornecedor. Com a quarta comunicação surge também uma indicação para se dirigir à Caritas a fim de estruturar um plano de amortização do seu débito. Em caso algum, no entanto, se procede ao desligamento ${ }^{23}$.

\footnotetext{
${ }^{20} \mathrm{Cfr}$. IEA - Energy Access Outlook 2017.

${ }^{21}$ Cfr. o Relatório Energy poverty and vulnerable consumers, cit., p. 48.

${ }^{22} \mathrm{Cfr}$. o Relatório Energy poverty and vulnerable consumers, cit., p. 53.

${ }^{23} \mathrm{Cfr}$. o Relatório Energy poverty and vulnerable consumers, cit., p. 56.
} 
As soluções com mais potencial são, evidentemente, aquelas que apostam no incremento da eficiência energética dos imóveis, servindo simultaneamente o interesse geral de redução do consumo de energia (sobretudo, se proveniente de fontes fósseis) e o interesse particular de redução do custo da factura energética. Esta via, apresentando-se como a mais rentável no longo prazo, pode gerar resistência consoante a situação do residente: proprietário sem ónus, proprietário com ónus (uma hipoteca sobre o imóvel) ou arrendatário. Os primeiros serão mais sensíveis à mudança, uma vez que esta se reflectirá directamente sobre os seus gastos; os segundos podem sentir-se pressionados por despesas de amortização dos ónus para aí desviando todo o seu esforço; e os últimos, não sendo donos do imóvel, restringir-se-ão, se tanto, a alterações mínimas (por exemplo, mudança de uma janela de um quarto), uma vez que não têm a propriedade do imóvel.

Também aqui a União Europeia tem feito algum trabalho, cumprindo referir o artigo 7, n 7, alínea a) da Directiva 20 I 2/27/UE, que aqui se reproduz:

"7. No âmbito do regime de obrigação de eficiência energética, os Estados-Membros podem:aa) Incluir requisitos com uma finalidade social nas obrigações que impõem em matéria de economias de energia, nomeadamente exigindo que uma parte das medidas de eficiência energética seja aplicada prioritariamente aos agregados familiares afetados pela precariedade energética ou à habitação social; (...)"

Esta norma permite, por exemplo, que um Estado-Membro imponha como condição do arrendamento de imóveis a obtenção de determinado nível registrado no certificado energético (que é obrigatório na transacção e arrendamento de imóveis), ou que só permita que o senhorio aumente a renda do imóvel caso implemente medidas de eficiência energética - podendo prever-se incentivos financeiros a favor dos senhorios que demonstrem maiores dificuldades de suportação dos encargos em razão da superior necessidade de investimento que os imóveis podem exigir.

Antecipando resistências, temos o exemplo concreto da Irlanda, com o recente programa Warmth and Well being scheme (programa Calor e Bem-Estar, 20 I6). Aqui, o Estado financia a reforma das habitações de Dublin em que residam consumidores vulneráveis com mais de 55 anos e também crianças com doenças respiratórias crónicas $^{24}$. Já o Reino Unido lançou, em 2013, o Green Deal, que consistia num mecanismo de incentivo a proprietários e empreendedores e passava por implementar medidas de eficiência energética nos imóveis utilizados para habitação ou negócio, sem custos de partida, contratando uma empresa envolvida no programa que se fará pagar

\footnotetext{
${ }^{24}$ Minister Naughten announces $€ 10 m$ for Warmth \& Wellbeing in 2017 https://www.hse.ie/eng/services/news/media/pressrel/minister-naughten-announces- $€ 10 \mathrm{~m}$-forwarmth-wellbeing-in-2017
} 
pelo fornecedor de energia. $\bigcirc$ consumidor amortizava a dívida contraída através de poupanças na factura energética em determinado período de tempo, sendo que o "empréstimo" tinha uma base real, ou seja, vinculava o imóvel, e não o seu proprietário, que poderia mudar ao longo do tempo ${ }^{25}$.

Certo é que as medidas de incremento do desempenho energético dos edifícios, se bem que envolvendo um custo que pode ser significativo (consoante o estado do imóvel e a necessidade da sua adaptação aos novos parâmetros) no curto prazo, revelam consideráveis benefícios, directos e indirectos, de longo prazo: de uma banda, reduzem as importações de combustíveis estatais; baixam o valor da factura energética do consumidor; contribuem para a criação de emprego na área da eficiência energética, na produção de equipamentos, montagem, manutenção e certificação; de outra banda, reduzem as despesas de saúde porque aumentam a qualidade de vida dos consumidores vulneráveis; incrementam o consumo de bens e serviços não relacionados com a energia, pois libertam rendimentos; travam as emissões de dióxido de carbono, sobretudo quando a poupança energética se reflicta em diminuição de uso de fontes fósseis.

\section{UMAPONTAMENTO SOBRE A POBREZA ENERGÉTICANO BRASIL}

Brasil assistiu, em meados dos anos 1990, a um aumento muito significativo do consumo de energia eléctrica, fruto do desenvolvimento económico alavancado pelo Plano Real, atingindo a um valor nacional de 83,5 TW/h no ano 2000. O sector residencial passava então a ser responsável por 1/4 do consumo de energia do País ${ }^{26}$.

No Brasil, a pobreza energética manifesta-se nas duas vertentes analisadas: por um lado, nas zonas rurais, o problema que vem sendo resolvido desde o início do século XXI prende-se com a questão do acesso à rede e com a utilização de biomassa para aquecimento das habitações, com os riscos e debilidades inerentes; por outro, nas regiões urbanas, os problemas detectados são, nas zonas mais pobres (favelas), ao nível da vulnerabilidade - com falta de meios para custear a factura energética, muitas vezes resolvidas com os famigerados "gatos" - e, em geral, no plano da eficiência energética dos edifícios, sobretudo na dimensão da refrigeração.

Cumpre fazer referência, nessa sede, ao programa do Governo Federal Luz para Todos (Programa Nacional de Eletrificação Rural Luz para Todos, criado pela Lei $n^{\circ}$

\footnotetext{
${ }^{25}$ Sobre o programa, que não teve sucesso e terminou em 20 I5, com apenas cerca de 15.000 intervenções realizadas, veja-se https://www.gov.uk/green-deal-energy-saving-measures

${ }^{26}$ Cfr. Roberto SCHAEFFER et alli., Energia e pobreza: problemas de desenvolvimento energético e grupos sociais marginais em áreas rurais e urbanas do Brasil, Santiago do Chile, 2003, pp. 2 I segs — disponível aqui: http://archivo.cepal.org/pdfs/2003/S038528.pdf
} 
10.762, de II de novembro de 2003). O programa tinha como meta conectar dois milhões de famílias à rede de energia elétrica (90\% delas abaixo da linha de pobreza) e atualmente mais de três milhões de famílias encontram-se já ligadas à rede ao abrigo do programa, com base num investimento de mais de vinte bilhões de reais, dos quais cerca de 3/4 provenientes do Governo Federal (o restante provém de Governos estaduais e empresas distribuidoras). Este programa, coordenado pelo Ministério de Minas e Energia, tem participação da Eletrobrás e de vários agentes sociais, dentre os quais as próprias comunidades.

A lógica do programa, por se revelar contrária ao modelo de mercado das empresas do ramo da eletricidade, assenta primordialmente no apoio público - uma vez que as concessionárias têm pouco interesse, em razão do alto custo/fraco lucro, na eletrificação das zonas rurais mais isoladas. A subsidiação do Governo é a fundo perdido com recursos provenientes da Conta de Desenvolvimento Energético. A Reserva Global de Reversão fornece financiamento a uma taxa de juros de 5\% ao ano com 24 meses de carência, amortização em dez anos e $1 \%$ de mora (taxa percentual sobre o atraso do pagamento), mais I \% ao ano para a comissão de reserva de crédito e a taxa de administração. Os estados disponibilizam recursos a título de subvenção económica, também a fundo perdido, e a distribuidora participa com recursos próprios.

Para as situações de vulnerabilidade, o Governo brasileiro criou a tarifa social, pela Lei $n^{\circ} 12.212$, de 20 de janeiro de 2010 , e pelo Decreto $n^{\circ} 7.583$, de 13 de outubro de 20 I I. Para se habilitar ao benefício, o candidato, singular ou familiar, deve cumprir um dos requisitos descritos seguintes: i) a família estar inscrita no Cadastro único para Programas Sociais do Governo Federal (Cadastro Único), com renda familiar mensal per capita menor ou igual a meio salário mínimo nacional; ii) a pessoa receber o Benefício de Prestação Continuada da Assistência Social, nos termos dos artigos 20 e 2 I da Lei n 8.742, de 7 de dezembro de 1993; iii) a família estar inscrita no Cadastro Único com renda mensal de até três salários mínimos, com pelo menos um membro que seja portador de doença ou deficiência cujo tratamento, procedimento médico ou terapêutico, requeira o uso continuado de aparelhos, equipamentos ou instrumentos que, para o seu funcionamento, demandem consumo de energia elétrica.

Esse mecanismo é indutor da redução de consumos, pois quanto menos gastar maior é a taxa de desconto - para um consumo mensal igual ou inferior a $30 \mathrm{~kW} / \mathrm{h}$, 65\%; para um consumo mensal igual ou inferior a $100 \mathrm{~kW} / \mathrm{h}, 40 \%$; para um consumo mensal igual ou inferior a 220 kW/h, 10\%; acima deste último padrão de consumo, não há desconto.

No plano da eficiência energética dos edifícios, o Brasil ainda não prevê incentivos à implementação de medidas no sector residencial. Existe o programa PROCEL EDIFICA, desde 2009-2010, que constitui base de um esquema de certificação energética de imóveis tanto para fins comerciais como habitacionais; essa certificação, porém, só é obrigatória para edifícios públicos, e apenas desde 20 I 4. O Banco Nacional de Desenvolvimento Económico e Social criou uma linha de financiamento designada 
Linha de Apoio ao Comércio e Serviços que visa apoiar projectos de investimento ligados ao incremento da eficiência energética no sector de comércio e serviços, bem como no Complexo Turístico Nacional.

Importa aludir, por último, à possibilidade de o consumidor gerar a própria energia por meio de regimes de micro e miniprodução de electricidade a partir da cogeração ou fontes renováveis, desde a Resolução Normativa ANEEL 484, de 2012 , podendo ainda vender o excedente à rede. Essa Resolução foi desenvolvida em 201 6, estabelecendo a possibilidade de rebater créditos de energia pelo produtor/consumidor (ou prosumidor), abrindo a porta à geração distribuída no seio de condomínios e criando a figura da "geração compartilhada"27. Essas soluções, não interferindo directamente com a questão da pobreza energética nem com a eficiência energética, acabam por empoderar o consumidor e torná-lo mais consciente dos seus gastos, induzindo sustentabilidade e poupança.

\section{NOTAS FINAIS}

A pobreza energética é um fenómeno que só recentemente começou a ser estudado e pode-se entender constituir apenas uma dimensão daquilo a que já se chamou "justiça energética". Esta envolve diversas questões de distribuição inequitativa de recursos energéticos, tanto do ponto de vista do acesso à energia, como do reassentamento de comunidades para construção de grandes infraestruturas de produção de energia, como ainda do passivo de decisões energéticas - v.g. , relacionadas com o armazenamento de resíduos nucleares ou com o imperativo de descarbonização em razão do aquecimento global ${ }^{28}$.

No que mais directamente releva para esta breve síntese, julgamos dever sublinhar duas ideias essenciais: no que toca à erradicação da pobreza energética na sua forma mais básica de garantia do acesso à energia eléctrica, políticas públicas de incentivo à produção de energia são fundamentais, sobretudo por esquemas como o microcrédito

\footnotetext{
${ }^{27}$ Para mais detalhes sobre estas figuras, cfr. http://www.aneel.gov.br/destaques-distribuicao//asset_publisher/zRFisxBAsbz9/content/geracao-distribuida-introducI/656827? inheritRedirect=false\&redirect $=$ http\%3A\%2F\%2Fwww.aneel.gov.br\%2Fdestaques -distribuicao\%3Fp_p_id\%3DI0I_INSTANCE_zRFisxBAsbz9\%26p_p_lifecycle\%3D0\%26p_p state\%3Dnormal\%26p_P_mode\%3 Dview\%26p_p_col_id\%3 Dcolumn2\%26p_p_col_pos\%3D2\%26p_p_col_count\%3D6

${ }^{28}$ Sobre o conceito e manifestações do conceito, veja-se B. K. SOVACOOL et alli., Energy decisions reframed as justice and ethical concerns, in Energy Justice, 2016 - disponível aqui: https://qmro.qmul.ac.uk/xmlui/bitstream/handle//23456789//6209/Sovacool\%20Energy\%20 decisions\%20reframed\%20as\%20justice\%20and\%20ethical\%20concerns\%202016\%20Acce pted.pdf?sequence $=$ I
} 
e o incentivo às indústrias de equipamentos de geração de energia renovável; no que tange à pobreza energética na sua forma mais sofisticada, ou seja, na vertente da promoção da eficiência energética, as políticas públicas que tornem as exigências de desempenho energético dos edifícios obrigatórias para os novos edifícios (sobretudo na lógica dos nearly zero energy buildings) e promovam programas de adaptação do património edificado, associadas a incentivos à indústria da construção e manutenção de equipamentos relacionados com sistemas de aquecimento e arrefecimento e isolamento térmico, são igualmente indispensáveis.

Como os recursos públicos são escassos, será importante fazer financiar essas iniciativas por meio de verbas que, no primeiro grupo de casos, deverão, por uma questão de responsabilidade comum mas diferenciada, ser canalizados em larga medida dos Estados desenvolvidos para os Estados em desenvolvimento (quer directamente pelos Governos, quer por investidores privados) e, no segundo grupo de casos, por quantias provenientes de Fundos de Carbono (alimentados por impostos sobre o carbono e por lucros de venda de títulos de emissão de $\mathrm{CO}_{2}$ em leilões, entre outros) ou Fundos de Eficiência Energética (suportados por taxas de realização de auditorias energéticas e por penalizações pecuniárias por não cumprimento dos parâmetros de eficiência energética, entre outros).

A transição para um modelo de geração distribuída, com consumidores a gerar, consumir e vender energia renovável à rede, e com o surgimento de comunidades energéticas, pode constituir um forte incentivo à erradicação da pobreza energética, em qualquer das categorias identificadas. $\bigcirc$ exemplo da Serra Leoa, relatado no Relatório da ONG Power for all, intitulado Decentralized renewables: from promise to progress (Energia renovável descentralizada: de promessa a progresso) ${ }^{29}$ é bem ilustrativo da mudança que um programa de apoio à democratização da produção de energia pode gerar num Estado em desenvolvimento - acesso à rede para todos em 2025, com ligação de 250.000 lares logo em 2016 (ano de arranque).

${ }^{29}$ Decentralized renewables: from promise to progress, March 2017, p. 9 - disponível aqui: https://staticl .squarespace.com/static/532f79fae4b07e365bafl c64/t/58e3f73ce4fcb5a3a09898 55/I 49 | 334979777/Decentralized-Renewables-From-Promise-to-Progress-March-20 I7.pdf A Power for all constituiu uma task force com o Ministério da Energia da Serra Leoa, e com vários actores privados no sentido de dinamizar o mercado das energias renováveis no País. Em menos de seis meses, com a criação de uma Associação Nacional para as Energias Renováveis, a implementação de uma política de isenções fiscais na compra de equipamentos de geração de energia renovável, a promoção de campanhas de sensibilização para a importância da produção de energia renovável e ainda o apoio do Fundo Monetário Internacional a uma iniciativa de estruturação de um esquema de microcrédito. 
Outra metodologia, descrita no Relatório da Agência Internacional de Energia Energy Access Outloook $2017^{30}$, realça as virtudes do microcrédito na implementação de esquemas de produção descentralizada em zonas em que haja cobertura de rede de telecomunicações móveis, mas não rede eléctrica. Trata-se do modelo de pagamento Pay-As-You-Go (PAYG), no âmbito do qual os consumidores usam os seus celulares para pagar um custo fixo inicial para o dispositivo, que geralmente se traduz num pacote que inclui painel solar, bateria de armazenamento e electrodomésticos, que vão sendo amortizados em pagamentos parcelados. Esse modelo é promissor porque funde microcrédito com geração de energia fotovoltaica, cujos equipamentos se encontram numa fase de desenvolvimento tecnológico que os torna cada vez mais acessíveis.

A geração distribuída pode igualmente incrementar os índices de eficiência energética em Estados desenvolvidos, pois o estatuto de prosumidor alerta os utentes dos serviços energéticos para aspectos benéficos de poupança, uma vez que o que poupam não só não pagam como pode constituir lucro na venda à rede. A geração distribuida reveste, assim, múltiplas vantagens no plano da política energética, tanto no campo da sustentabilidade do sistema e da transição para um modelo energético hipocarbónico, como no da eficiência energética, tornando os consumidores mais conscientes da sua pegada energética.

Certo é que a pobreza energética deve constituir um novo ponto na agenda política dos governos dos Estados desenvolvidos e em desenvolvimento, uma vez que se prende, inelutavelmente, com um direito tão básico como o direito à vida, em condições dignas e que permitam o livre desenvolvimento da personalidade em situação de igualdade material entre cidadãos, bem como com direitos de participação política. Nas palavras de BIROL, "promover a satisfação de necessidades humanas básicas, como alimentação e habitação, deve constituir o ponto focal de qualquer estratégia de erradicação da pobreza. Os serviços energéticos ajudam a essa satisfação. Por isso, podemos afirmar que o acesso à energia é um pré-requisito do desenvolvimento humano"3! .

\section{REFERÊNCIAS}

BIROL, Faith. Energy Economics: a place for energy poverty in the Agenda?, The energy journal, 2007/3.

BOARDMAN, Brenda. Fuel poverty: from cold homes to affordable warmth. Londres, |99|.

\footnotetext{
${ }^{30}$ Já citado.

${ }^{31}$ Faith BIROL, Energy Economics... cit., p. 4.
} 
BOUZAROVSKI, Stefan. Energy poverty in the European Union: Landscapes of vulnerability, in Wiley Interdisciplinary Reviews: Energy \& Environment, 20 | 4/3.

BOUZAROVSKI, Stefan, e Sergio TIRADO HERRERO. The energy divide: Integrating energy transitions, regional inequalities and poverty trends in the European Union, in European Urban and Regional Studies, 2017/1.

BRADSHAW, J., e S. HUTTON. Social policy options and fuel poverty, in Journal of Economic Psychology, I 983/3, p. 249.

DE FOCATIS, Marinella. Povertà energetica e cliente vulnerabile tra ragioni di stato e di mercato, in Esperienze regolatorie europee a confronto nel settore dell'energia : atti del convegno Aiden (Milano, 3 dicembre 2015), coord. de Eugenio Bruti Liberati, Marinella De Focatiis, Aldo Travi, Milão, 2017.

GONZÁLEZ-EGUINO, Mikel. Energy poverty: an overview, in Renewable and sustainable energy reviews, 2015.

MAXIM, Alexandru, et alli. Implications and Measurement of Energy Poverty across the European Union, in Sustainability, 2016/5.

REDDY, A., Energy and social issues, in Energy and the challenge of sustainability, World Energy Council and UNEP, New York, 2000, p. 38. Disponível em: http://www.undp.org/content/dam/aplaws/publication/en/publications/environmentenergy/www-ee-library/sustainable-energy/world-energy-assessment-energy-andthe-challenge-of-sustainability World\%20Energy\%20Assessment-2000.pdf

SCHAEFFER, Roberto, et alli. Energia e pobreza: problemas de desenvolvimento energético e grupos sociais marginais em áreas rurais e urbanas do Brasil, Santiago do Chile, 2003, p. 21. Disponível em: http://archivo.cepal.org/pdfs/2003/S038528.pdf

SOVACOOL, B. K., et alli. Energy decisions reframed as justice and ethical concerns, in Energy Justice, 201 . Disponível e m : https://qmro.qmul.ac.uk/xmlui/bitstream/handle/I 23456789//6209/Sovacool\%20En ergy\%20decisions\%20reframed\%20as\%20justice\%20and\%20ethical\%20concerns $\% 202016 \% 20$ Accepted.pdf?sequence $=1$

THOMSON, Harriet, Carolyn SNELL, e Stefan BOUZAROVSKI, Health. Well/Being and Energy Poverty in Europe: A Comparative Study of 32 European Countries, in International Journal of Environmental Research and Public Health, 20 I 7/6, p. 584. 
Decentralized renewables: from promise to progress, March 2017. Disponível em: https://static I squarespace.com/static/532f79fae4b07e365bafl c64/t/58e3f73ce4fcb5 a3a0989855/I 49|334979777/Decentralized-Renewables-From-Promise-toProgress-March-2017.pdf

Good practice in energy efficiency (2016). Commission Staff working document (Accompanying the document Proposal for a Directive of the European Parliament and of the Council amending Directive 2012/27/EU on Energy Efficiency): https://ec.europa.eu/energy/sites/ener/files/documents/good_practice_in_ee_web.pdf

Energy poverty and vulnerable consumers in the energy sector across the EU: analysis of policies and measures, coord. de Steve Pye (UCL), Audrey Dobbins (USTUTT), Insight EU - Policy Report 2, maio de 2015, disponível em http://www.insightenergy.org

Health Impact of Low Indoor Temperatures, WHO Regional Office for Europe: Copenhaga, I985. Disponível e m: -http://www.theclaymoreproject.com/uploads/associate 1365/file/Health\%20Documents/WHO\%20-\%20health\%20impact\% 20of\%20low\%20indoor\%20temperatures\%20(WHO,\%20 I 985).pdf 


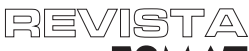

ESMAT

CARLA AMADO GOMES

REVISTA ESMAT

$228 \begin{aligned} & \text { ANO 10 - No } 15 \\ & \text { Pás. 211-228I IAN. AJun. } 2018\end{aligned}$ 